\title{
The Evolution of the Cryopreservation Techniques in Reproductive Medicine-Exploring the Character of the Vitrified State Intra- and Extracellularly to Better Understand Cell Survival after Cryopreservation
}

\author{
Pierre Vanderzwalmen ${ }^{1,2}$, Fabien Ectors ${ }^{3}$, Yannis Panagiotidis ${ }^{4}$, Maximilian Schuff ${ }^{1}$, \\ Maximilian Murtinger ${ }^{1}$ and Barbara Wirleitner ${ }^{1, *}$ \\ 1 NEXTCLINIC IVF Zentren Prof. Zech-Bregenz, 6900 Bregenz, Austria; pierrevdz@hotmail.com (P.V.); \\ m.schuff@ivf.at (M.S.); m.murtinger@ivf.at (M.M.) \\ 2 Centre Hospitalier Inter Régional Edith Cavell (CHIREC), 1180 Bruxelles, Belgium \\ 3 FARAH Research Center, Faculty of Veterinary Medecine, Liège University, 4000 Liège, Belgium; \\ fabien.ectors@ulg.ac.be \\ 4 Iakentro Advanced Medical Centre, 54250 Thessaloniki, Greece; infofr@iakentro.gr \\ * Correspondence: b.wirleitner@ivf.at
}

Received: 31 July 2020; Accepted: 15 September 2020; Published: 17 September 2020

\begin{abstract}
Nowadays, cryopreservation of gametes and embryos is a fundamental, integral, and indispensable part of infertility treatment or fertility preservation. Cryopreservation is not only needed for the policy of single embryo transfer and cryopreservation of surplus embryos, but for deferring embryo transfer in the case of ovarian hyperstimulation syndrome, uterine pathologies, and suboptimal endometrium built-up or when preimplantation genetic testing is needed. Several current strategies in assisted reproduction technology (ART) would be inconceivable without highly efficient cryopreservation protocols. Nevertheless, cryopreservation hampered for a long time, especially in terms of low survival rates after freezing and thawing. Only the technical progress during the last decades, namely, in regard to the implementation and advancement of vitrification, leveraged its application, and thus, even allows the cryopreservation of human oocytes-a process that is far from being easy. This review aims to provide a deeper insight into the physical processes of cryopreservation and to explore the character of the vitrified state in the extra and intracellular milieu in order to demonstrate that the common denominator to all cryopreservation procedures is the establishment of an intracellular amorphous condition that hinders the likelihood of crystallization.
\end{abstract}

Keywords: cryopreservation; cryobiology; vitrification; slow freezing; assisted reproduction techniques (ART); embryo; gamete; macromolecular crowding; aqueous solidification; colloidal solidification

\section{Cryopreservation: A Field of Emerging Interest}

Cryobiology is the science that studies the cellular behavior of biological material (e.g., gametes, embryos, tissues, organs) at low temperatures. From the very beginning, the challenge in the development of cryopreservation techniques was to cool down the biological material from room temperature to $-196^{\circ} \mathrm{C}$, while ensuring the cellular function and integrity of cell organelles and membranes after warming to develop subsequent in vitro or in vivo. 


\subsection{In the Animal Field}

Since the development of fundamental studies on cryopreservation of embryos, and the first birth of a mouse after freezing almost 50 years ago [1], this discipline has risen attention in a first instance in the area of embryo transplantation in domestic livestock species [2,3].

In the field of bovine embryo transplantation, the application of cryopreserved semen or embryos enabled semen and embryo transport to be more practical and cost-effective; remarkably, 30 years of international trade with frozen embryos has not resulted in the transmission of a single infectious disease agent [4].

In laboratory animal species, cryopreservation of embryos is an important strategy for conserving species and valuable strains of laboratory species [5].

The practice of genetic engineering has increased the number of mouse and rat lines to tenfold the actual number of lines, and thus, the maintenance costs of these animals have increased enormously. Most of these lines are generated for a particular purpose and may become unnecessary when the research evolves. These lines may still be useful in other jobs, but to maintain them involves a significant cost that can slow the progression of other research. The best solution to this problem is to cryopreserve these lines, thus avoiding keeping them as "metabolizing" animals by storing their embryos at $-196^{\circ} \mathrm{C}$ in liquid nitrogen $\left(\mathrm{LN}_{2}\right)$ [6].

\subsection{In the Human Field}

The development of various cryopreservation methods for application in many cell therapies for transplantation $[7,8]$ and for assisted reproduction technology (ART) $[9,10]$ is constantly progressing.

Meanwhile, cryopreservation of human oocytes and embryos has taken a prominent place in the fertility treatment. Modern IVF would be unthinkable without the current techniques. Cryopreservation of gametes and embryos has increasingly come into the focus for a multitude of indications. Freezing of surplus embryos became necessary with the implementation of hormonal stimulation resulting in the harvest of several oocytes per cycle. Cryopreservation of gametes, was originally implemented to maintain the chances to conceive in the case of oncological therapies (fertility preservation), and then extended to indications, such as Turner syndrome, autoimmune diseases, endometriosis, or preservation for societal reasons (Table 1).

Table 1. Indication for cryopreservation of embryos and gametes in ART.

\begin{tabular}{|c|c|}
\hline \multicolumn{2}{|r|}{ Zygote or Embryo Cryopreservation: } \\
\hline \multicolumn{2}{|r|}{$\begin{array}{l}\text { Surplus zygotes/embryos after IVF } \\
\text { Prevention of the risk for the ovarian hyper-stimulation syndrome (OHSS) } \\
\text { Prevention of transfer of embryos into the sub-optimal endometrial environment, due to hormonal } \\
\text { stimulation or uterine pathologies (e.g., uterine polyps or myoma) } \\
\text { Preimplantation genetic testing (PGT) }\end{array}$} \\
\hline \multicolumn{2}{|r|}{ Indications for Oocyte Cryopreservation: } \\
\hline \multicolumn{2}{|c|}{ - $\quad$ Fertility preservation } \\
\hline (a) & $\begin{array}{l}\text { Oncological conditions with chemo- or radiotherapy planned (especially in the case of alkylating } \\
\text { chemotherapeutic agents or high-dose radiation of the pelvis) }\end{array}$ \\
\hline (b) & $\begin{array}{l}\text { Premature ovarian failure (POF) with or without genetic predisposition or disorders associated } \\
\text { with diminished fertility (e.g., Turner-Syndrome) }\end{array}$ \\
\hline (c) & Surgery planned involving the ovaries (e.g., due to endometriosis) \\
\hline (d) & $\begin{array}{l}\text { Systemic diseases and subsequent therapies involving a decrease in oocyte quantity and quality } \\
\text { (e.g., rheumatic and autoimmune diseases, or chronic inflammation) }\end{array}$ \\
\hline (e) & Delay of childbearing \\
\hline \multicolumn{2}{|c|}{$\begin{array}{l}\text { No sperm available on the day of pick-up } \\
\text { Ethical or legal restrictions for embryo freezing } \\
\text { Oocyte donation cycles }\end{array}$} \\
\hline
\end{tabular}




\section{Evolution of the Cryopreservation Techniques in ART}

\subsection{Cryopreservation in the 1980s-1990s: Applied for a Limited Number of Indications, Why?}

The first birth of a baby after the transfer of a cryopreserved embryo was obtained with the standard slow freezing technique [11]. Soon, this technique was widely and very successfully applied for cleavage stage embryos, but also for fertilized oocytes (zygotes) worldwide.

However, the use of the slow freezing technique (SLF) for unfertilized oocytes showed extremely limited outcomes during the following 15 years, and its application was limited to scarce and urgent medical indications (e.g., fertility preservation for young women diagnosed with cancer). In addition, oocyte cryopreservation was the only alternative in the case of absence or delayed semen production. For other indications, such as oocyte banking or family planning, it was not considered reasonable to propose cryopreservation of oocytes. Patients had to be informed about the experimental character of oocyte cryopreservation and that one could not guarantee the success of the procedure for the long-term future. Further slow freezing of embryos at the blastocyst stage showed poor outcomes. Observation of low survival rates post-warming, was the main reason for the lack of enthusiasm to implement cryopreservation techniques in ART more widely.

\subsection{Slow Freezing and the Undesirable Events Associated with Ice Crystal Formation}

The slow freezing protocol includes a pre-equilibration step of oocytes or embryos in low concentrations of permeable cryoprotective agents (CPA $\sim 10 \% v / v)$ before the cooling step. Embryos were cooled down step-wise (max. $0.5{ }^{\circ} \mathrm{C} / \mathrm{min}$ ) in a programmable system, after artificial extracellular ice seeding is induced. During cooling, for each formation of an extracellular ice crystal, the cell will re-establish osmotic equilibrium by dehydration. Thereby, during cooling, cells continue to dehydrate intracellularly, reducing the risk for intracellular ice crystal formation until the straws are plunged into $\mathrm{LN}_{2}$.

The real challenge is to control the two damaging factors that can occur during the freezing procedure: (i) The intracellular formation and growth of ice crystals during the cooling and warming steps by recrystallization, due to inappropriate cooling rates or insufficient membrane permeability to allow re-equilibration by water efflux and; (ii) the formation of an excessive intra- and extracellular hypertonic environment by uncontrolled extracellular crystallization, that will induce a rise in the solute concentration, causing irreversible damage by a mechanism called the "solution effect" [12-15].

It emerges from the preceding studies that the common denominator that negatively affects post-thaw survival is uncontrolled ice crystal formation inside and outside the cell. This is the crucial factor directly affecting the success of the slow freezing technique. In fact, the cellular damage that cell encounters during the slow freezing procedure has often been attributed to the formation of intracellular ice, due to inappropriate dehydration and to uncontrolled extracellular crystallization.

\subsection{One Century Ago: The Rise of the Vitrification Concept}

In the mid-1990s, the development of more robust freezing techniques was a priority, since for many cancer therapies, the survival rates have risen tremendously, and the number of potential indications for cryopreservation was steadily increasing too. This faced the dilemma of growing demand, which could not be met, due to the lack of an effective cryopreservation technique.

In the search for alternative methods, one turned back to the basis of cryobiology published in the studies of Luyet [16]. Almost 80 years ago, Luyet highlighted that the intracellular control of the foci of nucleation and ice crystal formation is a crucial event that determines the viability of all cell types that go through cryopreservation. He stressed that the change in the state of aggregation from liquid water into ice crystals in the intracellular compartment must be considered principally as the first cause of cell death. To counteract the crystallization process, Luyet introduced an alternative concept called vitrification [16,17]. The general principle of vitrification is to convert a liquid into a glass-like amorphous solid that is free of any crystalline structures. 
But only from the early 1980s onwards did cryobiologists develop efficient vitrification protocols for embryo cryopreservation [18]. Many publications related to the understanding and development of the vitrification of murine embryos [19,20], and cattle [21] have emerged and demonstrated the advantage of this technique. However, it was not until the mid-1990s that the interest in vitrification with increasing success in outcome arose in the context of ART [22].

\subsection{At Which Temperature Do We Obtain a Glass-Like Amorphous Solid State?}

\subsubsection{Temperature and the Change of States of Pure Water during a Cooling Process}

In order to establish a vitrification protocol, it is essential to understand the following issues: (i) At which temperature $\left(\mathrm{T}^{\circ}\right)$ do we obtain a vitrified state, (ii) at which temperature range does crystallization occur, (iii) under which (additional) conditions do we reach a vitrified state, (iv) the change of physical and chemical states during temperature changes according to the type of solutions or environment.

Water molecules are the major component of cells. Luyet has already postulated that an excess of free water is incompatible with survival after cryopreservation, due to ice crystal formation disrupting the cellular organelles and structures [17]. In viable cells, water is the solvent for intracellular molecules, such as salts, acids, or bases, essential for cell function [23]. In cryopreservation, water is also the solvent for permeable and non-permeable CPA. Water has to be considered as the major player to be mastered during the cryopreservation process [24].

How can cells survive the cryopreservation process despite their high water content? Depending on the $\mathrm{T}^{\circ}$ (and atmospheric pressure), water exists in three physical states: Solid, liquid, and gaseous. Generally, when the temperature drops (winter conditions, storage in the freezer), the solidification of water is thought to be associated with the formation of ice crystals. However, for the cryobiologist, water can solidify in two distinct forms. From the liquid state, water can either solidify as a liquid crystal of pure water or, under extremely rapid cooling conditions above $100,000{ }^{\circ} \mathrm{C} / \mathrm{min}$, a spray of water converts as a solid without crystal formation [25-27]. It is then solidification of pure water, which is described as an amorphous or glassy state [28,29].

(A) The crystalline solid form of water

The formation of the crystalline solid form of water is shown on the left part of Figure 1. The changes in the physical states of pure water in correlation to the decreasing temperature $\left(\mathrm{T}^{\circ}\right)$ are presented. When the temperature falls below $0{ }^{\circ} \mathrm{C}$, aqueous fluids do not freeze immediately but first "supercool". The crystallization initiation temperature lies in a range between the equilibrium melting temperature $(\mathrm{Tm})$ and the homogeneous nucleation temperature $(\mathrm{Th})$. This zone is characterized by the phenomenon of supercooling and heterogeneous nucleation. Heterogeneous nucleation occurs when particles in water are present, promoting the formation of ice crystals. In the state of supercooling between $\mathrm{Tm}$ and $\mathrm{Th}$, there is a competition between the formation of crystallization nuclei and the disappearance of these same nuclei in the liquid. The water molecules remain extremely mobile and free to reorient themselves almost independently of each other. Hydrogen bridges between water molecules are formed and break, due to the continuous movement of the molecules. As long as the crystal formation has not reached a critical mass, the tendency to dislocate prevails, explaining why water can remain supercooled down to temperatures as low as $-40{ }^{\circ} \mathrm{C}$ [30].

As the temperature drops, the state of supercooling cannot indefinitely continue. The movement of water molecules slows down, and the critical mass of the crystal nucleus formation is finally sufficient to induce solidification as Th approaches [31,32]. Once nucleation seeds are formed, the structure becomes rigid, and nucleation seeds can aggregate into larger crystals. When Th is reached, the system ends up crystallizing uniformly even in the absence of any crystallization seeds and transforms into a stable state as a crystalline solid [33]. 


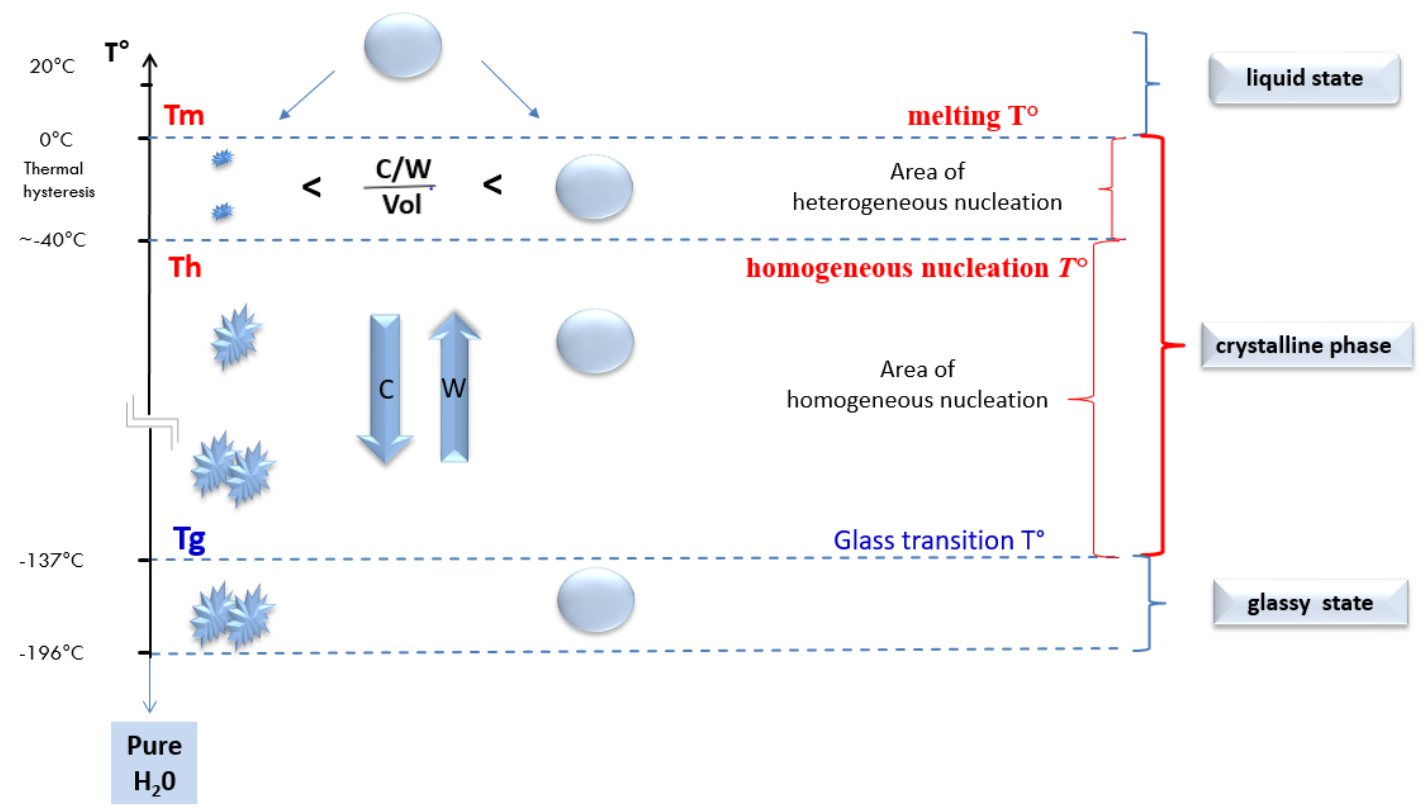

Figure 1. States of pure water during cooling/warming. On the left side of this one-dimensional phase diagram, the changes in the physical states of pure water in correlation to the decreasing temperature $\left(\mathrm{T}^{\circ}\right)$ are presented. Below Tm (melting temperature), heterogeneous nucleation can occur. Only after reaching a temperature below Th (homogeneous nucleation temperature) ice crystal formation without the presence of crystallization nuclei occurs. Solidification of pure water in a glassy solid form (vitrification) is achieved when the $\mathrm{T}^{\circ}$ decreases extremely rapidly (cooling speed; $\mathrm{C}$ ) below the glass transition temperature $(\mathrm{Tg})$.

(B) The glassy solid-state of water

Solidification of pure water in a glassy solid form (vitrification) is achieved when the temperature decreases extremely rapidly below the glass transition temperature ( $\mathrm{Tg}$; Figure 1 ). Is was found that $\mathrm{Tg}$ for pure water is $-137^{\circ} \mathrm{C}$ [34] and only possible with cooling (C) rates exceeding $100,000^{\circ} \mathrm{C} / \mathrm{min}$ to avoid spontaneous crystal nucleation when crossing the zone between $\operatorname{Tm}$ and $\operatorname{Tg}$ [22-24].

Below $\mathrm{Tg}$, the movement of water molecules is too slow to organize the start of crystallization, and the solution solidifies with water molecules arranged in a completely disordered state. In other words, under these experimental conditions of very rapid cooling rates, water has the ability to remain in a supercooled state. Thereby, low temperatures in association with an extreme increase in viscosity are important. These two factors induce that water molecules are no longer be able to organize themselves into a crystalline structure, and an amorphous or vitreous solid-state is achieved. Almost intact intermolecular bonds are typical of the liquid state that characterizes the amorphous or vitreous solid-state [28,29].

Figure 1 shows that lethal ice crystal formation occurs during the transit through Tm and Tg. In the case of pure water, the probability of reaching the glassy state during the lowering the $\mathrm{T}^{\circ}$ is dependent on the speed of cooling (C) and the volume (Vol) of the liquid. This can be expressed by the simple equation:

$$
\text { Probability of obtaining a vitrified state in pure water }=\frac{\mathrm{C}}{\mathrm{Vol}}
$$

At slow cooling rates, the formation of crystals is directly observed (pure water becomes a milky color); in contrast, at extremely high cooling rates (which are not applicable in our IVF laboratories), a glassy solid-state is observed when pure water reaches $\mathrm{Tg}$ (with transparent appearance). 


\subsubsection{Shifting of the Glass Transition Temperature ( $\mathrm{Tg}$ ) in Cryoprotectant Solutions}

During the development of the different cryopreservation techniques, it was soon recognized that biological material cannot survive at very low temperatures without the usage of water-soluble $\mathrm{CPA}$. Due to their polarity, CPA have a great capacity to form hydrogen bonds with water molecules, due to their hydroxyl residues (glycerol, ethylene glycol, 1-2 propanediol, propylene glycol) or sulfoxide groups (e.g., DMSO). Membrane diffusible CPA are not only highly soluble in the aqueous environment, but also intracellularly and can enter into the cell mainly through specific aquaporin channels. During incubation of cells with solutions containing CPA, a part of the intracellular free water will be replaced by a CPA solution. CPAs increase the viscosity and thereby lead to a slowdown of the molecular movements of the water [35]. An increase in viscosity results in (i) a delay of the nucleation phenomenon, (ii) a reduction of the growth rate of ice crystals, (iii) a limitation of the size of the crystals between $\mathrm{Tm}$ and $\mathrm{Tg}$, and (iv) an impairment of crystal formation in the case of the huge increase in viscosity during drop in the $\mathrm{T}^{\circ}$.

It has to be considered that $\mathrm{Tm}, \mathrm{Th}, \mathrm{Tg}$ for pure water are defined and constant (Figure 1). However, aqueous solutions (e.g., culture media containing salts, amino acids, and proteins, or cryopreservation solutions containing salts, amino acids, proteins, and CPA) show different $\mathrm{Tm}, \mathrm{Th}$, and $\mathrm{Tg}$. The shift in these parameters depends on the respective concentration and composition of solved molecules and CPA [23]. For each change in the concentration of salt or cryoprotectant $\mathrm{Tm}, \mathrm{Th}$ and $\mathrm{Tg}$ have a specific value. The shift of Tm, and consequently, Th and $\mathrm{Tg}$ can be visualized on a phase diagram divided into three zones corresponding to the different phases: (i) Liquid, (ii) crystalline solid, and (iii) glassy or amorphous solid (Figure 2) [36].

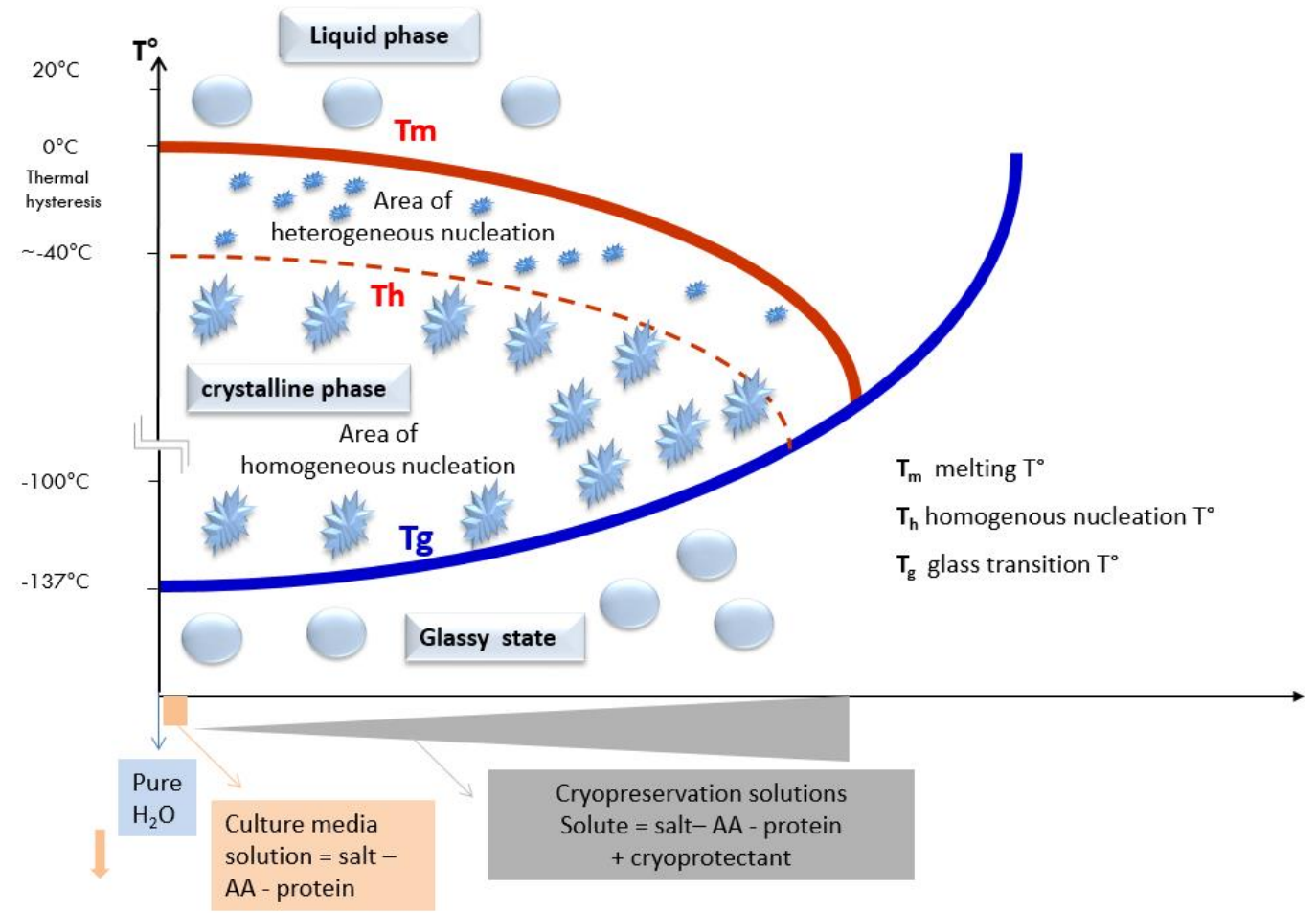

Figure 2. Phase diagram of different solutions during cooling/warming. In solutions, the content of salts, proteins, and other macromolecules, as well as cryoprotective agents (CPA), lead to an increase in viscosity. As a consequence, the melting temperature I decreases, and the glass transition temperature $(\mathrm{Tg})$ increases. Thereby, the temperature range where ice crystal formation occurs becomes substantially smaller, and the probability of obtaining a glassy state increases.

Above $\mathrm{Tg}$, the solutions are either supercooled or in a state of a crystalline solid. Below $\mathrm{Tg}$, a supercooled solution can go directly transform from a liquid state into a state called a glassy 
solid, or amorphous ice. It should be mentioned, however, that crystalline solid water formed at a temperature above $\mathrm{Tg}$ will remain crystalline when cooling down below $\mathrm{Tg}$. Therefore, to achieve a glassy solid-state $\mathrm{Tm}$ to $\mathrm{Tg}$ has to be passed without crystal formation.

\subsection{The General Principle of the Vitrification Technique}

2.5.1. The Concentration of CPA (Viscosity), Cooling/Warming Rates and Volume: Three Parameters to Control Achieving a Vitrified State

The fundamental issue in all vitrification methods is to achieve and maintain conditions inside and outside of the cells that guarantee an amorphous state throughout the cooling, as well as during the warming process. This is reached when solutes are sufficiently concentrated, or when cooling is of sufficient speed, that the increased viscosity inhibits nucleation and prevents the growth of ice crystals. From the binary phase diagram, we can intuitively deduct that when the concentration of $\mathrm{CPA}$ increases, $\mathrm{Tg}$ rises $\left(\mathrm{Tg}=-135^{\circ} \mathrm{C}\right.$ for pure water, $<-135^{\circ} \mathrm{C}$ for $\mathrm{CPA}$ solutions), and the amplitude of transit between $\mathrm{Tm}$ and $\mathrm{Tg}$ is shortened. The faster this temperature range is passed; the lower is the probability for ice crystal formation. As a consequence, the key to success to achieve a "glass-like" state in the extra- and intracellular compartment is to determine the optimal balance between the following three factors: (i) The speed of cooling and warming (generally C/W; $200{ }^{\circ} \mathrm{C} / \mathrm{min}$ to $20,000{ }^{\circ} \mathrm{C} / \mathrm{min}$; in some systems even $1000{ }^{\circ} \mathrm{C} / \mathrm{min}-100,000{ }^{\circ} \mathrm{C} / \mathrm{min}$ ), (ii) the optimal solute viscosity, and (iii) the volume of the drop of the vitrification solution [35,37-39]. Whereas, in pure water, $\mathrm{C}$ determines the solidification in a glassy state, and in solutions, the content of solved molecules and CPA have to be considered.

This is highlighted by the equation of Yavin and Arav [40] for the probability of obtaining a vitrified state:

$$
\text { Probability of obtaining a vitrified state in solutions }=\frac{\mathrm{C} / \mathrm{W} \times \text { Conc.CPA }}{\mathrm{Vol}}
$$

The faster the cooling rate, the lower the concentration of $\mathrm{CPA}$ in the solution is required to achieve vitrification.

\subsubsection{How to Prepare Oocytes and Embryos before Plunging Them into $\mathrm{LN}_{2}$ ?}

Before cooling of oocytes or embryos down to $-196{ }^{\circ} \mathrm{C}$ in $\mathrm{LN}_{2}$, the intracellular compartment has to be prepared to allow the achievement and maintenance of an intracellular vitreous state [38]. To reach this objective, in nearly all vitrification protocols, the biological material is exposed in a minimum of two steps to gradually increasing concentrations of non-vitrifying solution (nVS) and vitrifying solution (VS). Thereby, intra- and extracellular viscosities are increased to an extent, which ensures that the liquid water molecules will solidify at a sufficient speed, so that a rearrangement into a crystalline structure is extremely unlikely [41,42].

Practically, the nVS contains a mixture of cell-penetrating CPA, e.g., dimethyl sulfoxide (DMSO), ethylene glycol, 1,2-propanediol (PROH), or glycerol in concentrations ranging between 2.3-3.2 M [42,43]. The duration of exposure to the $\mathrm{nVS}$ at a defined temperature is of utmost importance and determines the concentration of intracellular CPA. The exposure time is determined by several biophysical factors, such as the membrane properties (cellular permeability to water and CPA), the type, mixture, and concentration of CPA, the surface/volume ratio of the cells, and the speed of cooling and warming. For example, in Figure 3, the biological material is exposed to the nVS until full equilibrium (recovery of the initial volume), meaning entrance of plenty of CPA molecules associated with water molecules. 


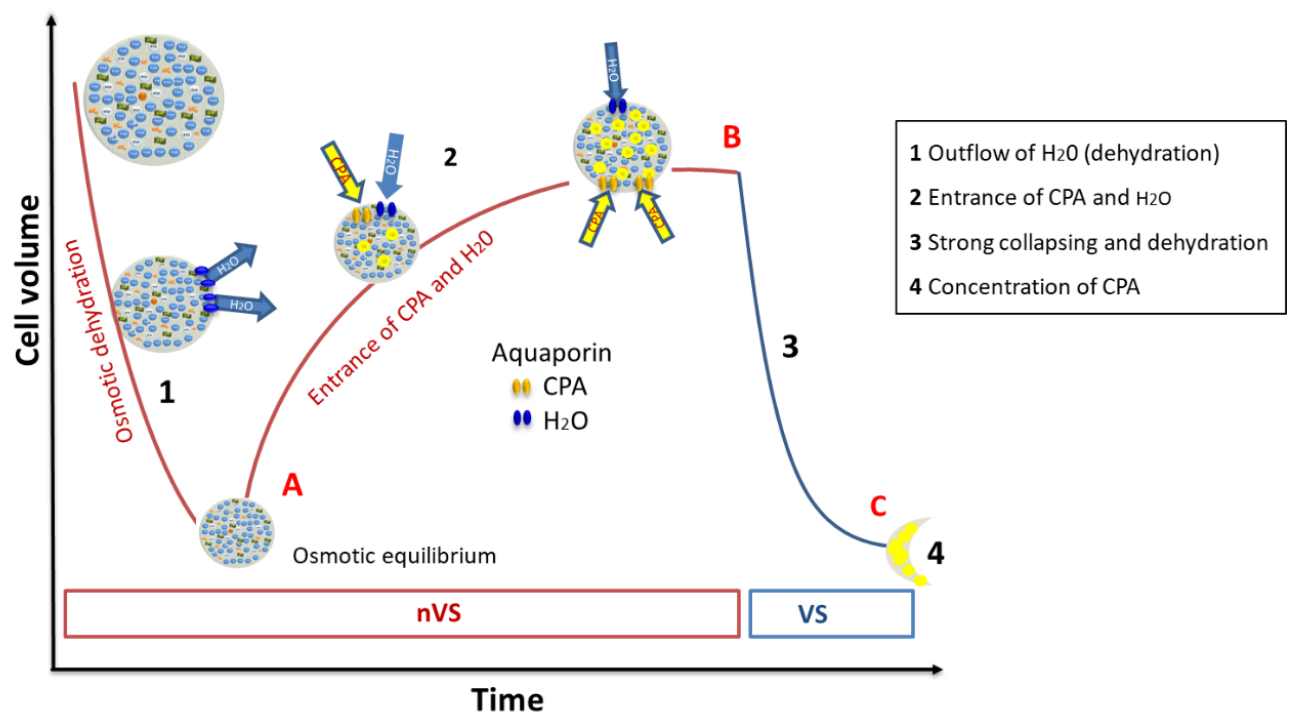

Figure 3. The biphasic reaction of a cell in the presence of non-vitrifying CPA solution (non-vitrifying solution (nVS); penetrating and non-penetrating $\mathrm{CPA}$ ) and vitrifying CPA solution (vitrifying solution (VS); penetrating and non-penetrating CPA). Changes in cell volume and molecular changes are shown (blue dots represent free water molecules, green and red dots cellular macromolecules, yellow dots $\mathrm{CPA})$. During incubation of oocytes or embryos with nVS, the cells dehydrate in a first step as water flows out through the aquaporin channels (1). After reaching an osmotic equilibrium (A), the entrance of CPA, and to a lesser extent, of $\mathrm{H}_{2} \mathrm{O}$ follows (2). This is characterized by a small increase in volume (B). In the VS, strong dehydration occurs (3), leading to a concentration of CPA within the cell (4) and a strong decrease in cell volume (C).

In the final step, just before being plunged in $\mathrm{LN}_{2}$, embryos or oocytes are exposed for a short period (45-90 s) to a VS, containing very high concentrations of a mixture of penetrating CPA (4.8-6.4 M), non-penetrating CPA (e.g., sucrose or trehalose $0.5-0.75 \mathrm{M}$ or high molecular weights compounds, such as Ficoll). This last solution is highly concentrated with an osmolarity between $5500-6500 \mathrm{mOsm} / \mathrm{L}$. The physical aspect of this solution is that it stays transparent during cooling and warming, expressing the maintenance of a glassy vitrified state (Figure 3).

\subsection{Exploration of the Intracellular Compartment}

\subsubsection{Mode of Action of the High Concentrated VS}

As all CPA are potentially toxic, the VS was developed with the minimal concentration of penetrating CPA that permit to obtain and maintain a vitrified state. When exposing the oocytes or embryos to the VS, the extracellular compartment is encapsulated by the VS in the form of a vitrifying sheath. This sheath avoids extracellular ice crystal formation as this could lead to cell injury not only, due to crystallization, but also because of the "solution effect", a freeze-concentration of damaging solutes.

Due to the high osmolarity of the VS containing also non-penetrating CPAs, such as sucrose or trehalose, a fast shrinkage of the cytoplasm is observed following dehydration (Figure 3). The soluble components of the cytoplasm (amino acids, proteins, polymers, nucleotides, and other macromolecules) and the CPA that have previously penetrated into the cell during exposure to the nVS concentrate. This generates an intracellular environment favorable to the formation of a vitreous state before the cells are rapidly plunged into $\mathrm{LN}_{2}$. 
The probability of extracellular vitrification is in relation to the concentration of CPA and is represented by the following equation:

$$
\text { P Vit Extra cell } \left.=\frac{\frac{C}{W} \times \text { EC Conc CPA }}{\text { Vol }} \quad \text { EC (extracellular }\right)
$$

2.6.2. The Intracellular Concentration of Cryoprotectant Is Far below the Number of CPA in the Vitrifying Solution

One of the main concerns in vitrification was, and still is, the high concentrations of CPA in the VS This concern was the basis of several debates as it exceeds three- to four-fold the concentration of CPA in the former applied slow freezing technique (CPA solutions [CPsol] of 1.5 M). However, the vitrification protocol follows a different concept, including, e.g., dramatically shorter incubation times in the nVS and VS, limiting the time for CPA entrance. The hypothesis of high intracellular concentrations of CPA (ICCP) in vitrified cells was demystified in a recent study using cinematographic analysis. It was demonstrated that the ICCP is approximately $2.14 \mathrm{M}$ and thereby far below the CPA concentration of the VS solution (6.4 M) [44].

The finding of 2-fold differences between the concentration of CPA in the VS and the ICCP raises an important question. An aqueous solution containing 2.14 M penetrating CPA will directly crystallize. According to Luyet, the presence of ice crystals in the intracellular compartment is the principal cause of cell death $[16,45]$. Therefore, how can it be explained that oocytes and embryos survive the vitrification process even though that the ICCP is far below this threshold? Is the ICCP of $2.14 \mathrm{M}$ sufficient to inhibit the process of nucleation and crystallization without interfering with the integrity of the cells?

\subsubsection{Two Physical Arguments to Explain the Absence of Intracellular Crystallization}

Two hypotheses may support the absence of intracellular crystallization in the presence of a reduced concentration of CPA.

Intracellular Crowding and the Colloidal Vitrification

Glasses are always amorphous, but not all amorphous substances are glasses [46]. Such a statement leads us to reconsider the concept of the amorphous state, particularly in the intracellular compartment. If the vitrifying solution is a vitreous solution, i.e., vitreous amorphous, it is not the same with regard to the intracellular amorphous state, which cannot be qualified as vitrifying (glassy state).

According to Mochida et al. and Zhou et al., the osmotic dehydration process modifies the intracellular architecture in a way that the formation of intracellular ice crystals is inhibited despite a low ICCP [47,48]. In almost every cell, the cytosol is a crowded fluid in which many macromolecules, including proteins, amino acids, polymers, nucleotides, and others, are floating. The cytoplasm further contains cell organelles (e.g., vesicles, SER, mitochondria), and cytoskeletal structures. An increase in the concentration of intracellular macromolecules is called "macromolecular crowding". In freezing studies on bacterial cytoplasm, glass-like properties have been reported to differ from those outside the cell $[49,50]$. In Lactobacillus and several other organisms, it has been described that osmotic dehydration emphasizes the intracellular macromolecular crowding. Osmotic removal of water from the cytoplasm leads to a buildup in the concentration of intracellular solutes and an increase in the packing density of macromolecules. Therefore, viscosity progressively increases, which leads to a solidification by colloidal vitrification. The high viscosity and the reduced diffusion rates promote the formation of a colloidal glass (Table 2). In contrast, solidification in a conventional aqueous glassy state can be observed in pure water [51-53].

Following these previous studies on the intracellular behavior during dehydration, this leads to the consideration whether the probability of obtaining an amorphous state differs intraand extracellularly. Extracellularly primarily CPA concentrations dictate the viscosity, whereas 
intracellularly, the cytoplasmic dehydration and macromolecular crowding itself is essentially involved in increasing viscosity. Thus, amorphous extracellular and intracellular situations are fundamentally different (Table 2).

Table 2. Molecular organization in vitrification and crystallization.

\begin{tabular}{ccc}
\hline \multicolumn{2}{c}{ Vitrification } & Crystallization \\
\hline $\begin{array}{c}\text { No Molecular Organization Infinite Increase of Viscosity } \\
\text { Vitreous amorphous state }\end{array}$ & $\begin{array}{c}\text { Of a colloid: } \\
\text { Colloidal amorphous state }\end{array}$ & $\begin{array}{c}\text { Molecular Organization of Water } \\
\text { types of crystal structures } \\
\text { (hexagonal or cubic) }\end{array}$ \\
\hline $\mathrm{Tg}=-130{ }^{\circ} \mathrm{C}$ & $\mathrm{Tg}=<-100^{\circ} \mathrm{C}$ & $\mathrm{Tm}=-5^{\circ} \mathrm{C}$ \\
\hline $\begin{array}{c}\text { solidification in a state typical of } \\
\text { a liquid }\end{array}$ & $\begin{array}{c}\text { solidification is related to } \\
\text { dehydration of a colloid }\end{array}$ & $\begin{array}{c}\text { Solution effect }->\text { amorphous } \\
\text { vitrification between ice crystals }\end{array}$ \\
\hline Extracellular only & Intra- or extracellular & Extracellular only \\
\hline
\end{tabular}

Revision of the Classical Equation on the Probability of Achieving a Vitrifying State

The intracellular milieu is depending on the number of CPAs that enter the cells during the exposure in the nVS. According to the time of exposure, the colloidal solidification may result in different architecture, and the probability of vitrification is dependent on the different factors that are more or less predominant, following short or longer exposure (Table 2).

As a consequence, the classical equation for the probability of obtaining a vitrified state takes into account the three factors (i) speed of cooling and warming $\left(2000{ }^{\circ} \mathrm{C} / \mathrm{min}\right.$ to $20,000{ }^{\circ} \mathrm{C} / \mathrm{min}$ ), (ii) solute viscosity, and (iii) the volume of the vitrification solution has to be updated. The equation needs to contain a distinction between the intracellular and extracellular compartments. In the intracellular compartment, not only the concentration of CPA influences the intracellular viscosity, but also the degree of crowding. The equations are presented in Figure 4 and Table 2. To our knowledge, this is the first approach to revising the classical equation and providing additional parameters that determine the intracellular probability as a function of the degree of dehydration and the concentration of cryoprotectants.

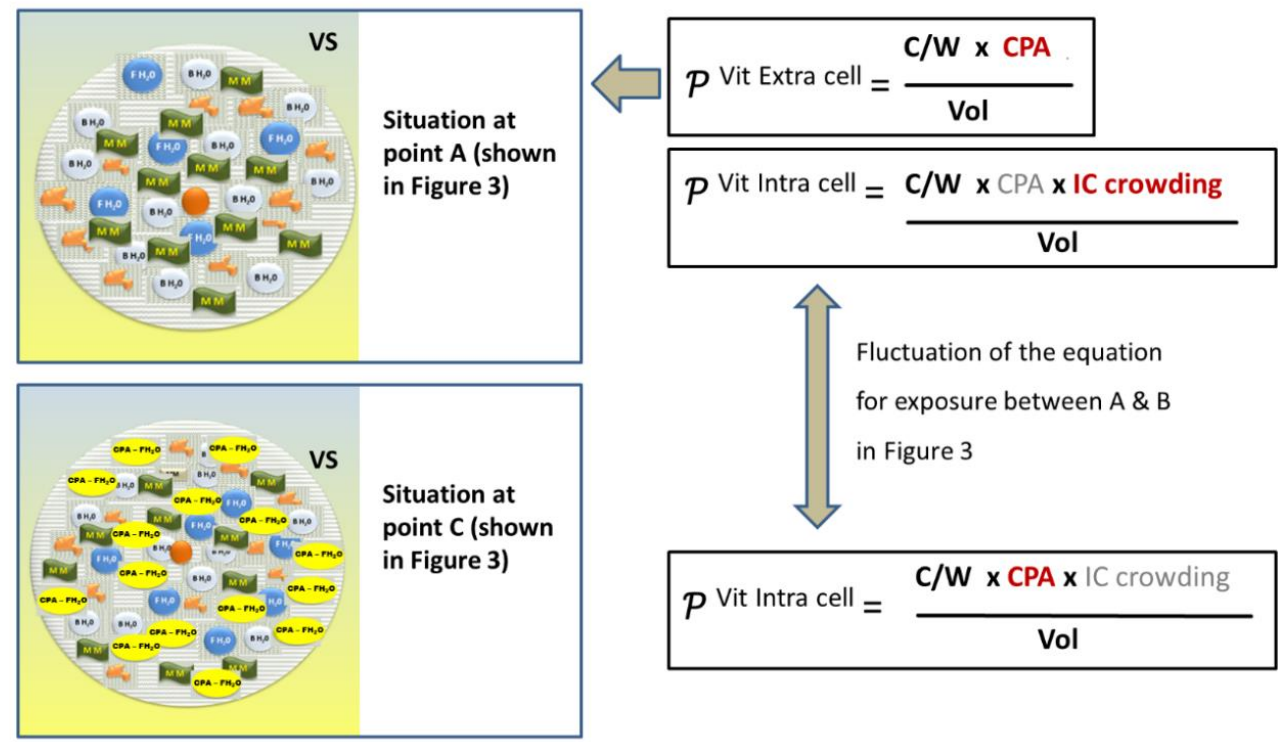

Figure 4. The probability of obtaining of a vitrified (glassy or colloidal) state in the extracellular fluid (P Vit extra cell) depends on the speed of cooling and warming $(\mathrm{C} / \mathrm{W})$, the concentration of $\mathrm{CPA}$, and the volume (Vol). Inside the cell (P Vit Intra cell), macromolecular crowding (IC crowding) has to be added as another factor. The influence of IC crowding fluctuates, dependent on the type of cells and the extent of dehydration. 
The Difference in the Intra- and Extracellular Glass Transition Temperature

Vitreous conditions are obtained when the $\mathrm{T}^{\circ}$ decreases. In bacteria, $\mathrm{Tg}$ was determined by scanning calorimetry, and authors showed that Tg differs totally in- and outside the bacterial cell [52]. They demonstrated that intracellularly colloidal vitrification is obtained at higher temperatures as compared to the extracellular aqueous vitrification. When bacteria were exposed to DMSO $(4.5 \% w / v)$, an intracellular $\mathrm{Tg}$ of $-51{ }^{\circ} \mathrm{C}$ was reported, whereas extracellular $\mathrm{Tg}$ was $-120^{\circ} \mathrm{C}$.

Going back to oocytes and embryos, this means that the intracellular conditions could be obtained inside the cell earlier than outside. The extracellular $\mathrm{Tg}$ in the VS technique is around $-125^{\circ} \mathrm{C}$. To our knowledge, there are no data regarding the intracellular Tg in oocytes and embryonic cells (Figure 5).

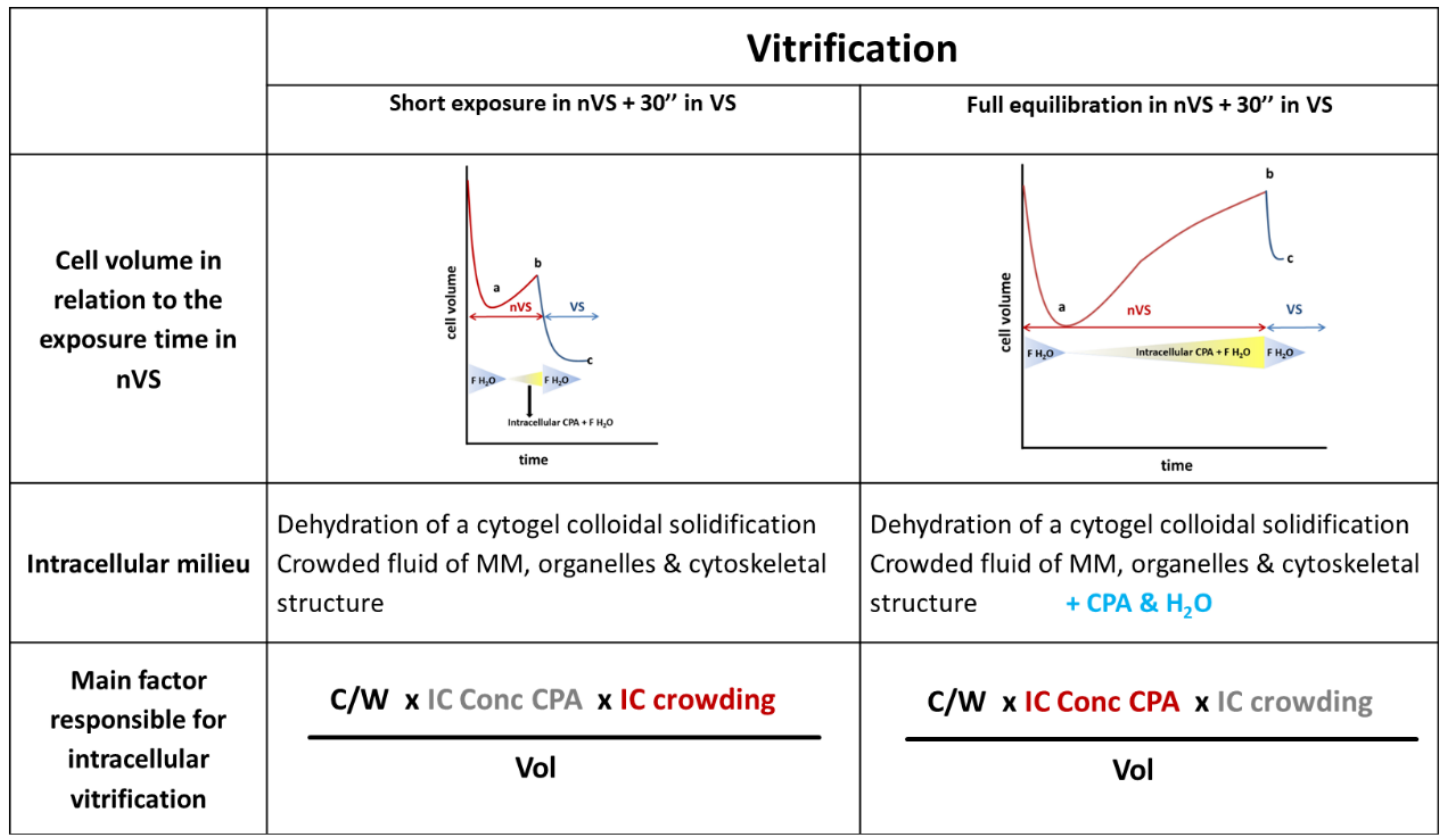

Figure 5. Response to CPA solutions and main factors responsible for intracellular vitrification. Short exposure to non-vitrifying solution(s) nVS and vitrifying solution (VS) result in a colloidal solidification mainly, due to macromolecular (MM) intracellular (IC) crowding. After first dehydration osmotic equilibrium is achieved (a), followed by an uptake of CPA with a small amount of water (b). In the final solution (VS) strong dehydration occurs (c). With longer incubations in nVS and VS removal of water and entrance of CPA is forced and a colloidal solidification occurs more influenced by the intracellular concentration of CPA.

\subsubsection{What Can Be Deducted from the Technique of Vitrification?}

We may conclude that two different types of amorphous states coexist that depend on the environment and may explain the difference in $\mathrm{Tg}$ in the extra- and intracellular compartments. The probability of reaching a vitrified state depends on the infinite increase of viscosity, and the highest viscosity of the extremely crowded cytogel reached a vitreous state after cell dehydration (Figure 4). Intracellular Tg is obtained at a higher temperature than outside the cell, even in the near-absence of CPA. The intracellular glassy state has the properties of a dense suspension of colloidal particles (colloid glass transition) rather than that of a molecular glass, such as in the extracellular medium (solution glass transition). The conditions of the extracellular vitrification are more drastic and need a very rapid and deep cooling in the presence of a high concentration of CPAs to reach a $\mathrm{Tg}$ of $-130{ }^{\circ} \mathrm{C}$. Such extracellular conditions are much more unstable and impose the physical conditions needed to achieve successful vitrification in the whole system. 


\subsection{Intracellular Vitrification: A Common Denominator for All Successful Cryopreservation Procedures}

It is well recognized that the absence of intracellular crystallization is the main factor ensuring the survival of biological material subjected to any kind of cryopreservation process. This statement, in combination with the above-described theory regarding differences between the intra- and extracellular vitrified states, raises the question of whether differences also exist in the cryopreserved states of various applied cryopreservation methods (Table 3).

Table 3. Characteristics of the different types of cryopreservation techniques.

\begin{tabular}{cccccc}
\hline $\begin{array}{c}\text { Cryopreservation } \\
\text { Technics }\end{array}$ & \multicolumn{2}{c}{ Vitrification } & $\begin{array}{c}\text { Slow } \\
\text { Freezing }\end{array}$ & $\begin{array}{c}\text { Ultra-Rapid } \\
\text { Freezing }\end{array}$ & $\begin{array}{c}\text { Sperm } \\
\text { Vitrification }\end{array}$ \\
\hline $\begin{array}{c}\text { Short time in } \\
\text { nVS }\end{array}$ & $\begin{array}{c}\text { Long time in } \\
\text { nVS }\end{array}$ & & & Yes \\
\hline $\begin{array}{c}\text { Extracellular } \\
\text { crystallization }\end{array}$ & No & No & Yes & Yes & Yes \\
\hline $\begin{array}{l}\text { Intracellular } \\
\text { vitrification }\end{array}$ & Yes & Yes & Yes & Yes & Very low \\
\hline $\begin{array}{l}\text { Intracellular CPA } \\
\text { concentration }\end{array}$ & Low & High & High & Low & ++++ \\
\hline $\begin{array}{l}\text { Intracellular } \\
\text { crowding of MM } \\
\text { colloid }\end{array}$ & +++++ & ++ & ++++ & ++ & Low \\
\hline $\begin{array}{l}\text { Extracellular Tg } \\
\text { Intracellular Tg }\end{array}$ & Low & Low & low & $?$ & higher \\
\hline $\begin{array}{l}\text { Solution effect } \\
\text { during cooling }\end{array}$ & No & higher & higher & higher & No \\
\hline $\begin{array}{l}\text { CPA, cryoprotectant(s); MM, macromolecular; Tg, glass transition temperature; nVS, non-vitrifying solution; } \\
\text { ?: no data available; }+ \text { refers to intensity of intracellular crowding. }\end{array}$ & & No & No &
\end{tabular}

There are several approaches to cryopreserve gametes (oocytes or spermatozoa) and embryos; (i) the conventional vitrification protocol using a high concentration of permeable CPA and high cooling/warming rates; (ii) the slow freezing protocol with the application of substantially lower concentrations of permeable CPA and low cooling rate; (iii) the directional freezing with permeable $\mathrm{CPA}$ and precise control of the solution effect; (iv) the method for cryopreservation of spermatozoa without the use of permeable CPA.

Each method has its own technical aspects in terms of the intra- and extracellular solidification characteristics. However, the common denominator in all methods is that they are all based in one way on the principle of increasing intracellular viscosity. This may occur, due to dehydration during incubation in VS, in the presence of $\mathrm{CPA}$, or due to dehydration during cooling because of the extracellular ice crystal formation (Figure 4).

The term vitrification should not only refer to a specific cryopreservation technique, but also to the vitrified state itself. The state of vitrification must be considered as present in all cells that survive cryopreservation, independent of the cryopreservation method applied, including also the SF technique.

In slow freezing, after equilibration with a permeable CPA $(\sim 10 \% v / v)$, the biological material is cooled down slowly. During cooling, ice crystal formation is induced in the extracellular solution (seeding). By each ice crystal that is formed, the osmolarity of the extracellular solution increases, inducing the outflow of water from the intracellular compartment, due to the increased osmotic pressure. If this procedure is performed sufficiently slow, the majority of the intracellular free water content leaves the cell to form extracellular ice crystals. Cell volume shrinks, and the intracellular concentration of macromolecules and CPA increases, resulting in an intracellular viscosity favorable to 
the formation of a vitreous state. The increasing viscosity associated with extracellular ice formation leads to intracellular vitrification. It has been reported that a $10 \% v / v$ glycerol solution reaches a concentration of approximately $67 \% w / w$ when slowly cooled down to $-38{ }^{\circ} \mathrm{C}$.

Similar observations are also reported in the study of Vanderzwalmen and colleagues [44]. The investigators could demonstrate that the ICCPs in vitrified zygotes are, in contrast to common belief, even lower than those observed in zygotes after an SF procedure. SF has been the standard cryopreservation method for more than 25 years, without being fully aware of the presence of a vitrified intracellular state obtained with a very high ICCP. We assume that for both, SF and conventional vitrification procedures, the common factor that creates an increase in the intracellular viscosity is based on the dehydration phase. In SF, dehydration occurs during external ice crystal formation, whereas in vitrification, dehydration takes place during the exposure to nVS and VS.

Intracellular vitrification is also present in the cryopreservation of sperm from different species (human [54], equine [55], even if the term vitrification applied in this context can be confusing from a methodological point of view.

The process of vitrification of spermatozoa is far different compared to the protocols applied for oocytes and embryos, as for sperm, CPA is applied in very low concentrations or even absent. This is because spermatozoa possess a very dense cytoplasm in which free water is naturally nearly absent [56]. The low concentration of extracellular CPA does not impair the apparition of extracellular ice crystals moving in the liquid phase to the right side of the phase diagram. What can be assumed about the intracellular compartment? In sperm, the low amount of CPA is sufficient to remove free water present in the cytoplasm, and after the fast cooling process, a non-crystalline solidification of the cytoplasm takes place. Thus, cell dehydration is a common phenomenon shared by all cryopreservation techniques which promote cell survival.

\section{Conclusions}

Grasping the physical-chemical" principles of cryopreservation is essential for understanding how and why gametes and embryos survive cryopreservation. Cryopreservation is a process that has evolved naturally, due to the adaption of many species to the extracellular environment. In response to subzero temperatures, microorganisms, insects, fishes, and amphibians produce specific antifreeze proteins, glycoprotein, or polysaccharides to preserve cellular integrity. Dehydration occurs naturally when temperatures drop, and ice crystals are formed in the extracellular environment of unicellular organisms-creating an increase osmolarity and outflow of water. The result is an increase in intracellular viscosity, and finally, supercooling. Studying the phenomenon of natural cryopreservation, different protocols evolved to cryopreserve human gametes and embryos. However, various types of cells respond differently to the methods used, dependent on their intracellular viscosity, the content of free water, and the membrane permeability for water and CPA. The specific application of permeable or non-permeable CPA, their concentrations, and the speed of cooling or warming are imminently success factors.

Regardless of the protocol used for cryopreservation, the common denominator for cell survival after cryopreservation is the achievement of an intracellular colloidal vitrified state. In an aqueous solution, a glassy vitrified state can be observed following ultra-fast cooling. In contrast, the intracellular compartment will be vitrified, due to an immense increase in viscosity after dehydration, macromolecular crowding, and uptake of CPA.

We reconsider the basic equation for obtaining an amorphous state. In this equation, the viscosity simply reflects the concentration of CPA. In the intracellular compartment, in addition to CPA, other parameters are involved. This includes intracellular macromolecular crowding, which reflects the intracellular fluidity. Macromolecular crowding increases during exposure to the CPA solutions, due to dehydration and influx of CPA. To our knowledge, this is the first approach that reconsiders the classical equation that involves only three parameters to determine the probability of obtaining an amorphous state. 
Discrimination between these two different physical states helps to understand why cryopreservation techniques work. Furthermore, it explains, why in the vitrification protocol, relatively low intracellular (but higher extracellular concentrations of CPA) are necessary to achieve an optimal outcome.

Cryopreservation has become an essential application in ART, for which the success of many other therapies would not have evolved without this technique. The in-depth exploration and knowledge questioning the underlying chemical and physical principles presented in this review will be the basis for understanding, optimizing, and discussing the potentially harmful effects of cryopreservation on pregnancy and neonatal outcomes.

Funding: This research received no external funding.

Conflicts of Interest: The authors declare no conflict of interest.

\section{References}

1. Whittingham, D.G.; Leibo, S.P.; Mazur, P. Survival of mouse embryos frozen to -96 degrees and -269 degrees C. Science 1972, 178, 411-414. [CrossRef] [PubMed]

2. Vatja, G. Vitrification in animal reproduction: Vitrification of embryos using open pulled straws. In Vitrification in Assisted Reproduction. A User's Manual and Trouble-Shooting Guide; Tucker, M.J., Liebermann, J., Eds.; Informa Healthcare: London, UK, 2007; pp. 65-73.

3. Mandawala, A.A.; Harvey, S.C.; Roy, T.K.; Fowler, K.E. Cryopreservation of animal oocytes and embryos: Current progress and future prospects. Theriogenology 2016, 86, 1637-1644. [CrossRef] [PubMed]

4. Gordon, I. In vitro embryo production. In Reproductive Technologies in Farm Animals, 2nd ed.; Gordon, I., Ed.; CABI Pub: Cambridge, MA, USA, 2017; pp. 100-101.

5. Mochida, K.; Ogura, A. Cryopreservation of embryos in laboratory species. J. Mamm. Ova Res. 2010, 27, 87-92. [CrossRef]

6. Tsang, W.H.; Chow, K. Cryopreservation of embryos from model animals and human. In Current Frontiers in Cryobiology; Katkov, I., Ed.; InTech: Houston, TX, USA, 2012; pp. 259-290. Available online: https://www.intechopen.com/books/current-frontiers-in-cryobiology/cryopreservation-of-embryosof-model-animals-and-human (accessed on 28 August 2020).

7. Neubauer, J.C.; Beier, A.F.; Stracke, F.; Zimmermann, H. Vitrification in pluripotent stem cell banking: Requirements and technical solutions for large-scale biobanks. In Vitrification in Assisted Reproduction, 2nd ed.; Tucker, M.J., Liebermann, J., Eds.; CRC Press: Boca Raton, FL, USA, 2015; pp. 203-224.

8. Connan, D. Contribution à L'étude de la Cryopréservation des Cellules Souches Embryonnaires Humaines à Visée Thérapeutique. Thése Doctorat, Université de Liège, Liège, Belgique, 2013. Available online: https://orbi.uliege.be/handle/2268/157842 (accessed on 28 July 2020).

9. Courbiere, B.; Decanter, C.; Bringer-Deutsch, S.; Rives, N.; Mirallié, S.; Pech, J.C.; De Ziegler, D.; Carré-Pigeon, F.; May-Panloup, P.; Sifer, C.; et al. Emergency IVF for embryo freezing to preserve female fertility: A French multicentre cohort study. Hum. Reprod. 2013, 28, 2381-2382. [CrossRef]

10. Peccatori, F.A.; Mangili, G.; Bergamini, A.; Filippi, F.; Martinelli, F.; Ferrari, F.; Noli, S.; Rabaiotti, E.; Candiani, M.; Somigliana, E. Fertility preservation in women harboring deleterious BRCA mutations: Ready for prime time? Hum. Reprod. 2018, 33, 181-187. [CrossRef]

11. Zeilmaker, G.H.; Alberda, A.T.; Van Gent, I.; Rijkmans, C.M.; Drogendijk, A.C. Two pregnancies following transfer of intact frozen-thawed embryos. Fertil. Steril. 1984, 42, 293-296. [CrossRef]

12. Mazur, P. The role of intracellular freezing in the death of cells cooled at supraoptimal rates. Cryobiology 1977, 14, 251-272. [CrossRef]

13. Leibo, S.P. Fundamental cryobiology of mouse ova and embryos. In The Freezing of Mammalian Embryos; Elliot, K., Whelan, J., Eds.; Elsevier/Excerpta Medica/North-Holland: Amsterdam, The Netherlands, 1977; Volume 52, pp. 69-92. 
14. Mazur, P.; Cole, K.W. Influence of cell concentration on the contribution of unfrozen fraction and salt concentration to the survival of slowly frozen human erythrocytes. Cryobiology 1985, 22, 509-536. [CrossRef]

15. Pegg, D.E. Principles of Cryopreservation. In Cryopreservation and Freeze-Drying Protocols; Wolkers, W.F., Oldenhof, H., Eds.; Methods in Molecular Biology; Springer Science + Business Media: New York, NY, USA, 2015; Volume 1257, pp. 3-19.

16. Luyet, B. The vitrification of organic colloids and of protoplasm. Biodynamica 1937, 1, 1-14.

17. Luyet, B.; Rapatz, G. Patterns of ice formation in some aqueous solutions. Biodynamica 1958, 8, 1-68.

18. Rall, W.F.; Fahy, G.M. Ice-free cryopreservation of mouse embryos at 196 C by vitrification. Nature 1985, 313, 573-575. [CrossRef] [PubMed]

19. Scheffen, B.; Vanderzwalmen, P.; Massip, A. A simple and efficient procedure for preservation of mouse embryos by vitrification. Cryo Lett. 1986, 7, 260-269.

20. Vanderzwalmen, P.; Gaurois, B.; Ectors, F.J.; Massip, A.; Ectors, F. Some factors affecting successful vitrification of mouse blastocysts. Theriogenology 1988, 30, 1177-1183. [CrossRef]

21. Massip, A.; Vanderzwalmen, P.; Scheffen, B.; Ectors, F. Pregnancies following transfer of cattle embryos preserved by vitrification. Cryo Lett. 1986, 7, 270-273.

22. Vanderzwalmen, P.; Delval, A.; Chatziparasidou, A.; Bertin, G.; Ectors, F.; Lejeune, B.; Nijs, M.; Prapas, N.; Prapas, Y.; Van Damme, B.I.; et al. Pregnancies after vitrification of human day 5 embryos. Hum. Reprod. 1997, 12, 98. [CrossRef]

23. Benson, E.E. Cryopreservation Theory. In Plant Cryopreservation: A Practical Guide; Reed, B.M., Ed.; Springer: New York, NY, USA, 2008; pp. 15-32.

24. Chian, R.C. Cryobiology: An overview. In Fertility Cryopreservation; Chian, R.C., Quinn, P., Eds.; Cambridge University Press: Cambridge, UK, 2010; pp. 1-9.

25. Brüggeller, P.; Mayer, E. Complete vitrification in pure liquid water and dilute aqueous solutions. Nature 1980, 288, 569-571. [CrossRef]

26. Mayer, E.; Brüggeller, P. Vitrification of pure liquid water by high pressure jet freezing. Nature 1982, 298, 715-718. [CrossRef]

27. Dubochet, J.; McDowall, A.W. Vitrification of pure water for electron microscopy. J. Microsc. 1981, 124, RP3-RP4. [CrossRef]

28. Fahy, G.M.; Rall, W.F. Vitrification: An overview. In Assisted Reproduction: A User's Manual and Troubleshooting Guide; Tucker, M.J., Liebermann, J., Eds.; Informa Healthcare: London, UK, 2007; pp. 1-20.

29. Fahy, G.M.; MacFarlane, D.R.; Angell, C.A.; Meryman, H.T. Vitrification as an approach to cryopreservation. Cryobiology 1984, 21, 407-426. [CrossRef]

30. Van der Elsken, J.; Dings, J.; Michielsen, C.F. The freezing of supercooled water. J. Mol. Struct. 1991, 250, 245-251. [CrossRef]

31. Muldrew, K.; Acker, J.P.; Elliott, J.A.W.; McGann, L.E. The Water to Ice transition: Implications for living cells. In Life in the Frozen State; Fuller, B.J., Lane, N., Benson, E.E., Eds.; CRC Press: Boca Raton, FL, USA; New York, NY, USA; Washington, DC, USA, 2004; pp. 67-107.

32. Franks, F. Metastable water at subzero temperatures. J. Microsc. 1986, 141, 243-249. [CrossRef]

33. Starr, F.W.; Angell, C.A.; Stanley, H.E. Prediction of entropic and dynamic properties of water below the homogeneous nucleation temperature. Phys. A Stat. Mech. Appl. 2003, 323, 51-66. [CrossRef]

34. Angell, C.A. Liquid fragility and the glass transition in water and aqueous solutions. Chem. Rev. 2002, 102, 2627-2650. [CrossRef] [PubMed]

35. Mullen, S.F.; Critser, J.K. The Science of Cryobiology. In Oncofertility: Fertility Preservation for Cancer Survivors; Woodruff, T.K., Snyder, K.A., Eds.; Springer: New York, NY, USA, 2007; pp. 83-109.

36. Cocks, F.; Brower, W. Phase diagram relationships in cryobiology. Cryobiology 1974, 11, 340-358. [CrossRef]

37. Elliott, G.D.; Wang, S.; Fuller, B.J. Cryobiology Cryoprotectants: A review of the actions and applications of cryoprotective solutes that modulate cell recovery from ultra-low temperatures. Cryobiology 2017, 76, 74-91. [CrossRef] [PubMed]

38. MacFarlane, D.R.; Forsyth, M. Recent insights on the role of cryoprotective agents in vitrification. Cryobiology 1990, 27, 345-358. [CrossRef]

39. Fuller, B.J. Cryoprotectants: The essential antifreezes to protect life in the frozen state. Cryo Let. 2004, $25,375-388$. 
40. Yavin, S.; Arav, A. Measurement of essential physical properties of vitrification solutions. Theriogenology 2007, 67, 81-89. [CrossRef]

41. Fahy, G.M.; Levy, D.I.; Ali, S.E. Some emerging principles underlying the physical properties, biological actions, and utility of vitrification solutions. Cryobiology 1987, 24, 196-213. [CrossRef]

42. Vanderzwalmen, P.; Ectors, F.; Grobet, L.; Prapas, Y.; Panagiotidis, Y.; Vanderzwalmen, S.; Stecher, A.; Frias, P.; Liebermann, J.; Zech, N.H. Aseptic vitrification of blastocysts from infertile patients, egg donors and after IVM. Reprod. BioMed. Online 2009, 5, 700-7007. [CrossRef]

43. Vanderzwalmen, P.; Zech, N.H.; Ectors, F.; Stecher, A.; Lejeune, B.; Vanderzwalmen, S.; Wirleitner, B. Blastocyst transfer after aseptic vitrification of zygotes: An approach to overcome an impaired uterine environment. Reprod. BioMed. Online 2012, 6, 591-599. [CrossRef]

44. Vanderzwalmen, P.; Connan, D.; Grobet, L.; Wirleitner, B.; Remy, B.; Vanderzwalmen, S.; Zech, N.; Ectors, F.J. Lower intracellular concentration of cryoprotectants after vitrification than after slow freezing despite exposure to higher concentration of cryoprotectant solutions. Hum. Reprod. 2013, 28, 2101-2110. [CrossRef] [PubMed]

45. Luyet, B. The problem of structural instability and molecular mobility in aqueous solutions "solidified" at low temperatures. Biodynamica 1966, 10, 1-32. [PubMed]

46. Galashev, A.E. Vitrification and structural differences between metal glass, quasicrystal and Frank-Kasper phases. J. Struct. Chem. 1996, 37, 120-136. [CrossRef]

47. Mochida, K.; Hasegawa, A.; Li, M.W.; Fray, M.D.; Kito, S.; Vallelunga, J.M.; Lloyd, K.C.; Yoshiki, A.; Obata, Y.; Ogura, A. High Osmolality Vitrification: A New Method for the Simple and Temperature-Permissive Cryopreservation of Mouse Embryos. PLoS ONE 2013, 8, e49316. [CrossRef]

48. Zhou, E.H.; Trepat, X.; Park, C.Y.; Lenormand, G.; Oliver, M.N.; Mijailovich, S.M.; Hardin, C.; Weitz, D.A.; Butler, J.P.; Fredberg, J.J. Universal behavior of the osmotically compressed cell and its analogy to the colloidal glass transition: Version 2. Proc. Natl. Acad. Sci. USA 2009, 106, 10632-10637. [CrossRef]

49. Parry, B.R.; Surovtsev, I.V.; Cabeen, M.T.; O’Hern, C.S.; Dufresne, E.R.; Jacobs-Wagner, C. The Bacterial Cytoplasm Has Glass-like Properties and Is Fluidized by Metabolic Activity. Cell 2014, 156, 183-194. [CrossRef]

50. Nishizawa, K.; Fujiwara, K.; Ikenaga, M.; Nakajo, N.; Yanagisawa, M.; Mizuno, D. Universal glass-forming behavior of in vitro and living cytoplasm. Sci. Rep. 2017, 7, 15143. [CrossRef]

51. Hunter, G.L.; Weeks, E.R. The physics of the colloidal glass transition. Rep. Prog. Phys. 2012, 75, 066501. [CrossRef] [PubMed]

52. Fonseca, F.; Meneghel, J.; Cenard, S.; Passot, S.; Morris, G.J. Determination of Intracellular Vitrification Temperatures for Unicellular Micro Organisms under Conditions Relevant for Cryopreservation. PLoS ONE 2016, 11, e0152939. [CrossRef]

53. Mourão, M.A.; Hakim, J.B.; Schnell, S. Connecting the Dots: The Effects of Macromolecular Crowding on Cell Physiology. Biophys. J. 2014, 107, 2761-2766. [CrossRef]

54. Tao, Y.; Sanger, E.; Saewu, A.; Leveille, M.C. Human sperm vitrification: The state of the art. Reprod. Biol. Endocrinol. 2020, 18, 17. [CrossRef]

55. Álvarez, C.; González, N.; Luño, V.; Gil, L. Ejaculated compared with epididymal stallion sperm vitrification. Anim. Reprod. Sci. 2019, 211, 106205. [CrossRef]

56. Morris, J.G.; Acton, E.; Murray, B.J.; Fonseca, F. Freezing injury: The special case of the sperm cell. Cryobiology 2012, 64, 71-80. [CrossRef]

(C) 2020 by the authors. Licensee MDPI, Basel, Switzerland. This article is an open access article distributed under the terms and conditions of the Creative Commons Attribution (CC BY) license (http://creativecommons.org/licenses/by/4.0/). 